\title{
Arterial Supply of the Guinea Pig Mandible
}

\author{
T. G. BOYD, W. A. CASTELLI, and D. F. HUELKE \\ Department of Anatomy, University of Michigan, Ann Arbor, Michigan
}

It has been shown that the blood supply of the coronoid process, mandibular angle, and condyle of the rat, monkey, and man arises from arteries that supply the muscles attaching to these processes, and generally not from the inferior alveolar artery which primarily supplies the mandibular body and teeth. ${ }^{1-5}$ It is the purpose of this study to demonstrate the intraosseous blood supply of the guinea pig mandible with special reference to the regions of the condyle, coronoid process, and the mandibular angle.

\section{Materials and Methods}

To determine the arterial supply of the guinea pig mandible and the anatomy of the region, 33 animals were used. Red latex, vinyl acetate, china ink, or Teichmann's paste was injected into the common carotid arteries by use of glass syringes and 18gauge needles. Simultaneous bilateral injections, administered by constant hand pressure, adequately filled the arteries. Six heads received injections of red latex; three, vinyl acetate; four, china ink, and eight, Teichmann's paste, a mercury and zinc oxide mixture colored with cinnabar. ${ }^{1}$

The heads of the specimens into which vinyl acetate was injected were removed, bisected, and macerated in 10 percent potassium hydroxide. Those specimens that received the red latex injections were dissected to determine the artery-muscle relationships about the mandible. The mandibles of the specimens marked by injections of the china ink and Teichmann's paste were removed, bisected and prepared by the modified Spalteholtz technic. ${ }^{6}$

Five animals were dissected to study the arrangement of the masticatory muscles.

This investigation was supported, in part, by USPHS Research Grant DE-00895 from the National Institute of Dental Research, National Institutes of Health, Bethesda, $\mathrm{Md}$, and by Research Grant 1-SO1-FR-5321-01 from the General Research Support Branch, Division of Research Facilities and Resources, Bethesda, Md.

Received for publication February 10, 1967.
For reference, mandibles of 7 other animals were removed, cleaned of soft tissues, and bleached.

\section{Results}

The arteries supplying the guinea pig mandible originated from several sources. The inferior alveolar artery entered the bone through the mandibular foramen and distributed through the bone to the teeth, the body of the mandible, and the periodontium (Fig. 1). The condylar process received its blood supply through arteries that primarily distributed to the lateral pterygoid muscle and to the temporomandibular joint capsule (Fig. 1-3).

The angle of the guinea pig mandible is an extremely large, thin plate of bone. On the medial side, there is a fossa for the attachment of the medial pterygoid muscle. Some of the arteries to this muscle passed close to the periosteum of the bone (Fig. 1). Likewise, arterial twigs passed deep to the masseter muscle on the lateral side of the angle (Fig. 2). Thus, arteries supplying the mandibular angle arose from both medial and lateral muscular arteries via periosteal branches.

An arterial complex was found about the temporomandibular joint. Close to the origin of the maxillary artery, several small arterial twigs arose which passed to the temporomandibular joint capsule adjacent to the neck of the condylar process. In addition, vessels passed to the condyle from arteries that supplied the lateral pterygoid muscle.

Arterial branches to the coronoid process arose from a variety of sources (Fig. 1,2). The medial side of the coronoid process was supplied mainly by small twigs from the deep temporal artery (Fig. 1), as well as by branches of the intraorbital artery. In addition, arterial branches from the temporomandibular joint arterial complex passed around the lateral side of the tem- 


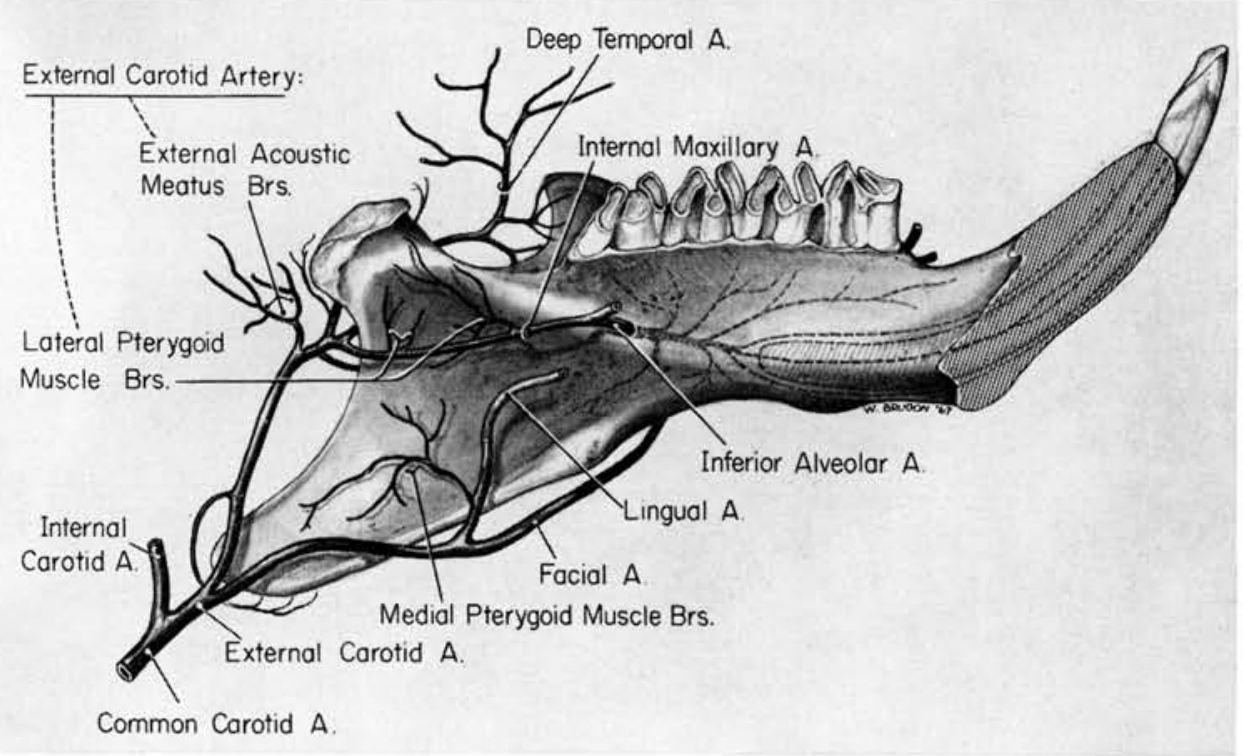

Frg. 1.-The arterial supply of the guinea pig mandible (medial view). Note that the condyle, angle, and coronoid process do not receive any arterial branches from the inferior alveolar artery.

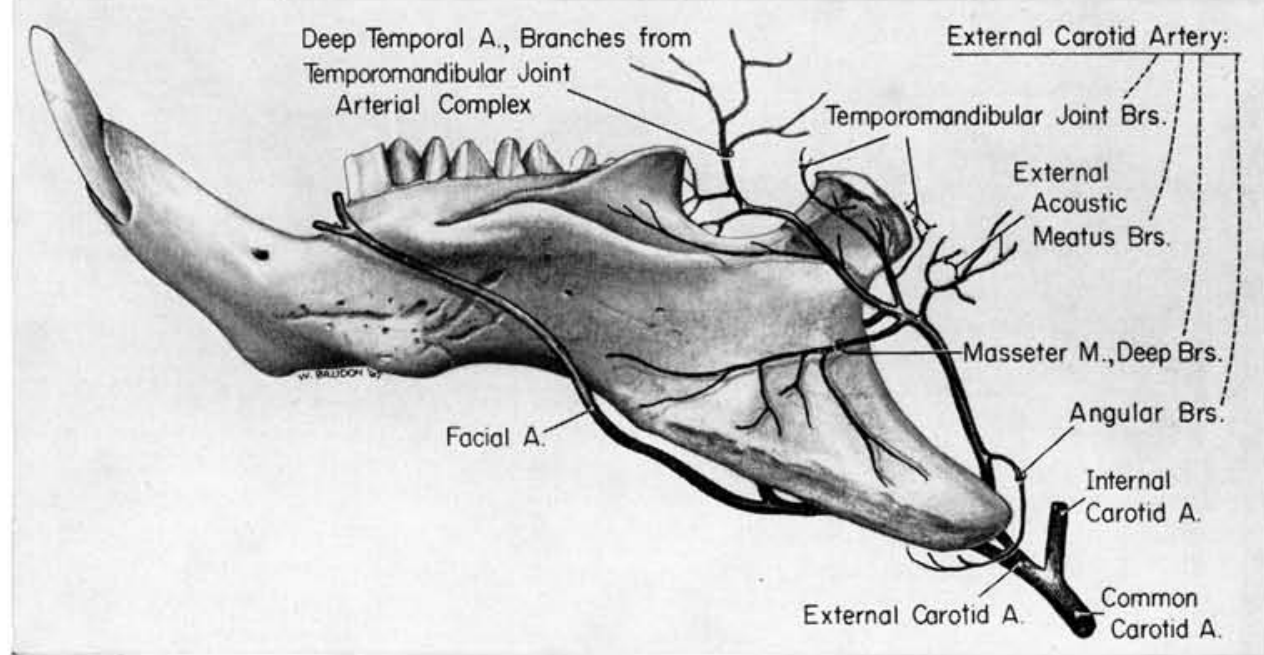

FIG. 2.-Guinea pig mandibular blood supply (lateral view). Branches to the angle run deep to the masseter muscle, whereas those to the temporomandibular joint region surround the capsule as well as pass to it through the lateral pterygoid muscle.

poromandibular joint capsule to the region of the lateral side of the coronoid process (Fig. 2).

No branches to the mandibular angle, condyle, or coronoid process arose from the inferior alveolar artery.

\section{Discussion}

The arterial supply to the mandible has been thought to come mainly from the inferior alveolar arteries. However, the findings of this study in the guinea pig and 


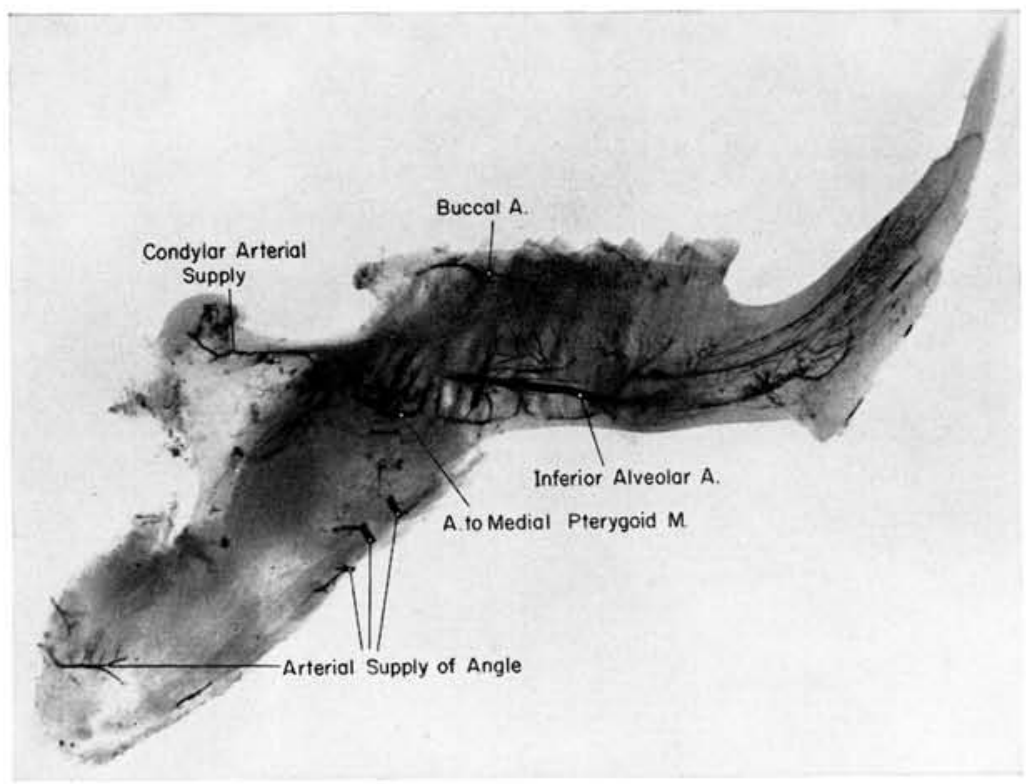

F1G. 3.-Cleared specimen of a guinea pig mandible into which zinc oxidemercury mixture was injected. The inferior alveolar artery distributes to the body, teeth, and periodontium. The ramus-mandibular angle, condyle, and coronoid process-receives arterial twigs from sources other than the inferior alveolar artery.

those previously mentioned in the rat, monkey, and man have shown that the mandible actually has a regional blood supply. The inferior alveolar artery supplies, in general, the body of the mandible, teeth, periodontium, and related regions, with the mandibular angle, coronoid, and condyloid processes having a separate and distinct arterial supply.

The mandible is not unlike most of the other bones of the body. Specifically, when the blood supply of the long bones of the extremities is considered, it is here that typically a regional blood supply will be seen. In general, the arteries in a region will supply the tissue in that specific region whether it be soft tissue or bone. About the head of the humerus, there is a regional blood supply differing from that of the shaft and separate from the anastomosis of vessels about the elbow joint.

A similar situation exists in the mandible. Regionally, muscles attaching to the mandibular angle (the medial pterygoid and the masseter muscles) are supplied by small arteries that send branches into the bone at the insertion of these muscles. Like- wise, about the condyle, vessels pass through the lateral pterygoid insertion to the condyle and temporomandibular joint capsule, and other arteries that supply the temporomandibular joint pass through the capsule to reach the head of the condyloid process and the mandibular neck. Also, the temporalis muscle, attaching to the coronoid processes, has vessels that follow along this muscle to its mandibular insertion to supply the coronoid process. Passing very close to the condyle and coronoid process is the maxillary artery, and branches either directly from it or those destined for other regions will send small arterial twigs into the region of the coronoid process and condyle.

\section{Summary}

By the use of various injection technics and by dissection, it has been shown that the vessels supplying the condyle, coronoid process, and mandibular angle in the guinea pig arose from branches that supply the muscles attached to these processes and not from the inferior alveolar artery. The inferior alveolar artery tends to limit its re- 
gion of supply to the body of the mandible, teeth, and periodontium. The mandible, like most of the other bones of the body, has a regional supply with the bony processes supplied by vessels that, in general, follow the muscles to their regions of insertion in the mandible.

\section{References}

1. Castelir, W. A. Vascular Architecture of the $\mathrm{Hu}-$ man Adult Mandible, J. Dent. Res., 42:786-792, 1963.
2. Castelli, W. A., and Huelke, D. F. The Arterial System of the Head and Neck of the Rhesus Monkey with Emphasis on the External Carotid System, Amer. J. Anat., 116:149-170, 1965.

3. Huelike, D. F., and Castelis, W. A. The Blood Supply of the Rat Mandible, Anat. Rec., 143:335$343,1966$.

4. Boyer, C. C., and Neptune, E. M. Patterns of Blood Supply to Teeth and Adjacent Tissues, $J$. Dent. Res., 41:158-171, 1962.

5. PERINT, J. Detailed Roentgenologic Examination of the Blood Supply in the Jaws and Teeth by Applying Radioopaque Solutions, Oral Surg., 2:2-20, 1949.

6. Spalteholtz, W. Die Arterien der Herzwant. Leipzig, Germany, S. Hirzel, 1924, p. 13. 